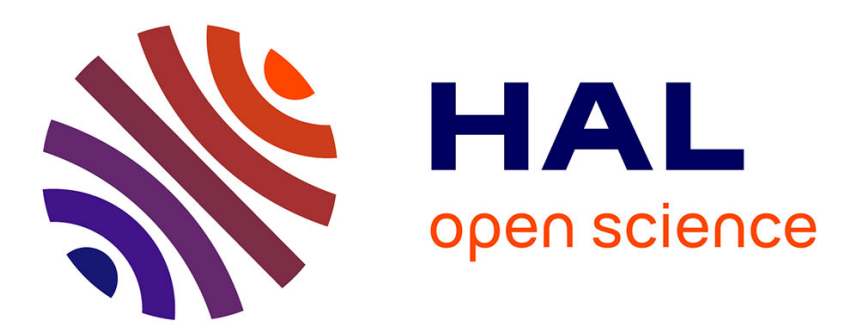

\title{
Numerical modeling of micro-friction and fiber orientation effects on the machinability of green composites
}

Faissal Chegdani, Mohamed El Mansori, Amen-Allah Chebbi

\section{- To cite this version:}

Faissal Chegdani, Mohamed El Mansori, Amen-Allah Chebbi. Numerical modeling of micro-friction and fiber orientation effects on the machinability of green composites. Tribology International, 2020, 150, pp.106380. 10.1016/j.triboint.2020.106380 . hal-03027761

\section{HAL Id: hal-03027761 \\ https://hal.science/hal-03027761}

Submitted on 27 Nov 2020

HAL is a multi-disciplinary open access archive for the deposit and dissemination of scientific research documents, whether they are published or not. The documents may come from teaching and research institutions in France or abroad, or from public or private research centers.
L'archive ouverte pluridisciplinaire HAL, est destinée au dépôt et à la diffusion de documents scientifiques de niveau recherche, publiés ou non, émanant des établissements d'enseignement et de recherche français ou étrangers, des laboratoires publics ou privés. 


\title{
Numerical modeling of micro-friction and fiber orientation effects on the machinability of green composites
}

\author{
Faissal Chegdani $^{\text {a, }}$, Mohamed El Mansori ${ }^{\mathrm{a}, \mathrm{b}}$, Amen-Allah Chebbi ${ }^{\mathrm{a}}$ \\ ${ }^{a}$ Arts et Metiers Institute of Technology, MSMP, HESAM Université, F-51006, Châlons-en-Champagne, France \\ b Texas A\&M Engineering Experiment Station, Institute for Manufacturing Systems, College Station, TX, 77843, USA
}

Keywords:

Natural fiber composites

Finite element modeling

Machining

Microscale friction

\begin{abstract}
A B S T R A C T
This paper aims to enhance the predictiveness of a finite element (FE) model for machining of natural fiber composites through a tribological approach based on the micro-friction phenomenon between the cutting tool and the components of the composite structure. A 2D micromechanical model for orthogonal cutting of flax fibers reinforced polylactic-acid (PLA) composites is considered in this study at different orientation of fibers. Results show that the numerical thrust forces are significantly affected by the variation of the micro-friction in the model. An optimized value of the micro-friction coefficient has been found to fit with the experimental results. The FE model provides the ability to calculate with good accuracy the effect of fiber orientation on the machinability of flax/PLA composites.
\end{abstract}

\section{Introduction}

Natural fiber reinforced polymer (NFRP) composites are nowadays used in different industrial sectors thanks to many technical, economic, and ecological advantages comparing to glass fiber reinforced polymer (GFRP) composites [1,2]. NFRP composites mean polymer composites that are reinforced with natural fibers, especially plant fibers (flax, hemp, jute ...). When the polymer matrix is also bio-based, the resulting NFRP composites can be called green composites. These kinds of eco-friendly materials are biodegradable and recyclable which contributes to a circular economy and a sustainable development [3-5].

Machining operations on NFRP composites generate many issues related to the cutting behavior of plant fibers within the composite [6-9]. Indeed, due to the complex cellulosic structure of natural fibers based on cellulose microfibrils toward the fiber axis, plant fibers are characterized by a high transverse elasticity that favors the fibers deformation and, consequently, avoids an efficient fiber shearing during the cutting processes [10]. This makes the machining of NFRP composites highly sensitive to the process parameters. Moreover, the natural fibrous reinforcement is characterized by a multiscale structure starting from the microscopic scale of the elementary fibers, then the mesoscale of the fibers bundle (the technical fiber), and the macroscale of the composite structure [10]. This multiscale structure makes the machinability analysis of NFRP composites highly sensitive to the analysis scale, typically for the investigation of the machined surfaces [10]. To resolve this issue, a new multiscale approach has been developed for the examination of the machinability of the NFRP composites. This approach postulates that the machinability analysis of NFRP composites requires the selection of the relevant scale which corresponds to the size of the natural fibrous reinforcement [11]. Therefore, before starting the analysis of the machined surfaces of NFRP composites, the natural fibrous reinforcement should be analyzed to measure the size of the considered fibrous structure (elementary fibers, technical fibers, fiber yarns ...). The topographic image size should correspond to the considered fibrous structure size in order to get an efficient discrimination of the effects of the different process parameters.

The new multiscale approach has shown its effectiveness on the machinability analysis of NFRP composites through an industrial application [11]. However, its application still encounters some limitations. Indeed, it is well known that the size of the natural fiber reinforcement shows a high variability due to the random size and shape of natural fibers within the same bundle [12], which is due to some environmental factors (pluviometry and sunshine) and mechanical factors of the extraction processes. Therefore, for the same fibers type that are grown in the same location, the relevant scale could be different from one harvest to another since the fibrous structure size may vary significantly. For these reasons, the multiscale approach should be re-applied to each fibers harvest, which is time and cost consuming.

\footnotetext{
* Corresponding author.

E-mail address: faissal.chegdani@ensam.eu (F. Chegdani).
} 


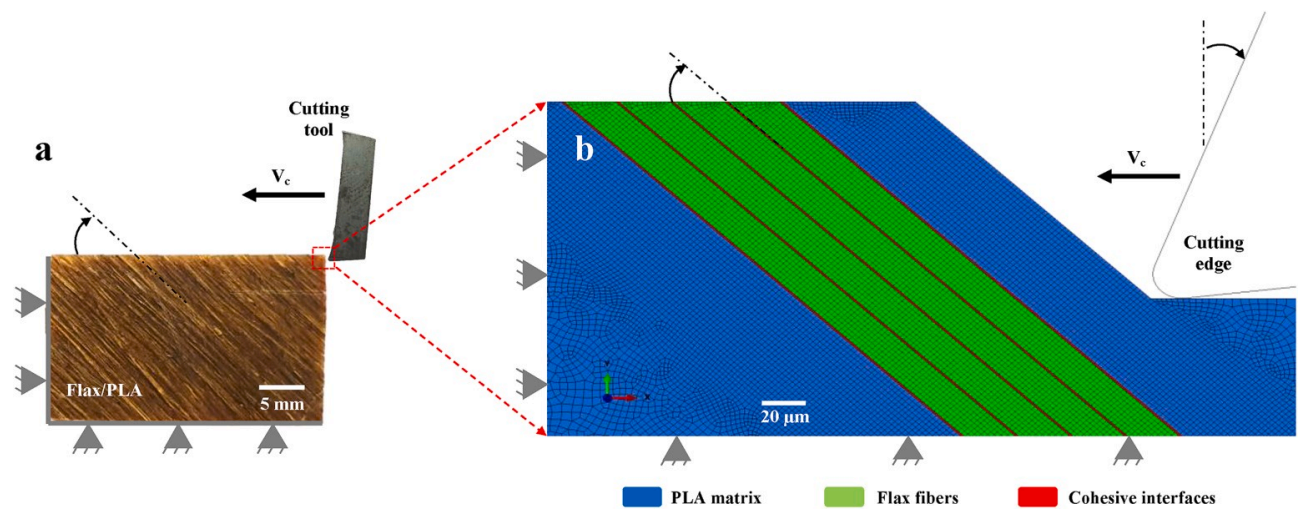

Fig. 1. (a) Image of the orthogonal cutting configuration at the real experimental scale. (b) Image of the $2 \mathrm{D}$ micromechanical cutting model showing the three composite components and the fiber orientation.

To avoid this issue, developing a numerical model for machining of NFRP composites could reduce considerably the time and the cost of the machinability analysis during the experimental validation of new NFRP composite products. For this aim, the authors have developed in a previous work a 2D finite element model at microscale to simulate the orthogonal cutting behavior of natural flax fibers reinforced polypropylene composites [13]. Unlike synthetic fibers (glass and carbon), flax fibers were modeled using an elastoplastic law and a ductile damage criterion. The finite element (FE) micromechanical model can reproduce qualitatively the cutting behavior of natural fibers during the machining operation at different cutting speed values. Quantitatively, the cutting forces are well reproduced by the FE model in terms of trend and magnitude. For the thrust forces, the trends are well reproduced by the FE model but there is a factor of $\sim 3$ for magnitude between FE results and experimental outputs [13]. The same phenomenon has been observed for the FE modeling of the machining of synthetic fiber composites $[14,15]$. The magnitude difference in thrust force results between the FE model and the experiments has been explained by the fibers spring back that is not considered in the numerical model. Nevertheless, no theoretical or experimental evidence can confirm this hypothesis.

A different approach is investigated in this paper to address the issue of the thrust force correlation in the FE modeling of NFRP machining. This approach is based on the machining tribology, especially the microfriction between the composite and the cutting tool. The micro-friction means the local friction between the cutting tool and each composite phase component at microscale (elementary natural fibers and polymer matrix). The considered investigation is motivated by previous authors works on the local micro-friction on NFRP composites by scratch-test experiments $[16,17]$. Indeed, the first scratch-test experiments were done with a diamond Berkovich tip indenter and the friction coefficient has been found around 0.4 for polypropylene (PP) matrix and around 0.5 for flax fibers [16]. These values were used in the previous FE model of machining [13]. However, the following scratch-test experiments were done with a Sapphire Berkovich tip indenter and the friction coefficient has been found around 0.2 for both PP matrix and flax fibers at the same scratching conditions as the experiments with the diamond indenter [17]. This indicates that the tool material causes a significant modification of the frictional properties in the case of NFRP composites. Therefore, the values of the micro-friction used in the previous FE machining model may be not appropriate because the experimental machining tests were performed by a carbide cutting insert. This could be the origin of the magnitude difference in the thrust forces of the FE machining model.

In this paper, the FE micromechanical model for machining of NFRP composites is used to investigate the effect of the micro-friction on the machining forces at different values of fiber orientation. A green composite is considered in this study and it is composed of flax fibers embedded in a natural polymer matrix of polylactic-acid (PLA). Moreover, the FE cutting behavior of flax fibers is compared to that observed with scanning electron microscope (SEM) on the experimental machined surfaces for each fiber orientation.

\section{Finite element modeling}

\subsection{Geometrical setup}

The FE model developed in Ref. [13] has been considered in this
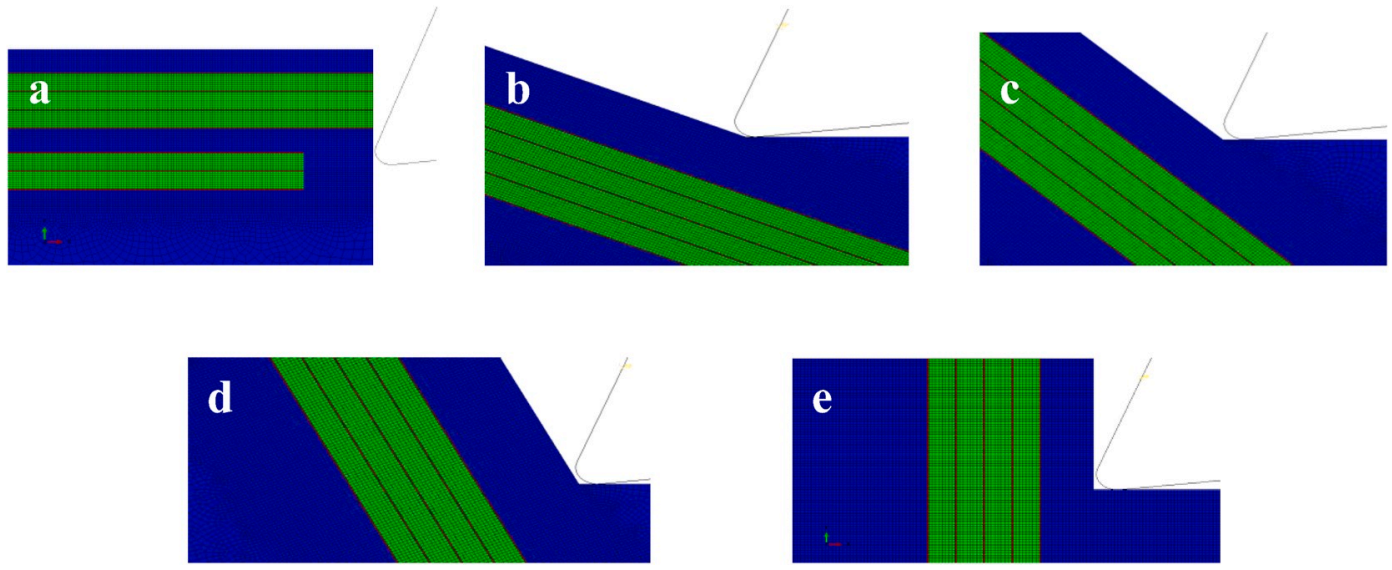

Fig. 2. Images of the model geometries at the different considered fiber orientations. (a) $\theta=0^{\circ}$, (b) $\theta=25^{\circ}$, (c) $\theta=45^{\circ}$, (d) $\theta=65^{\circ}$, and (e) $\theta=90^{\circ}$. 

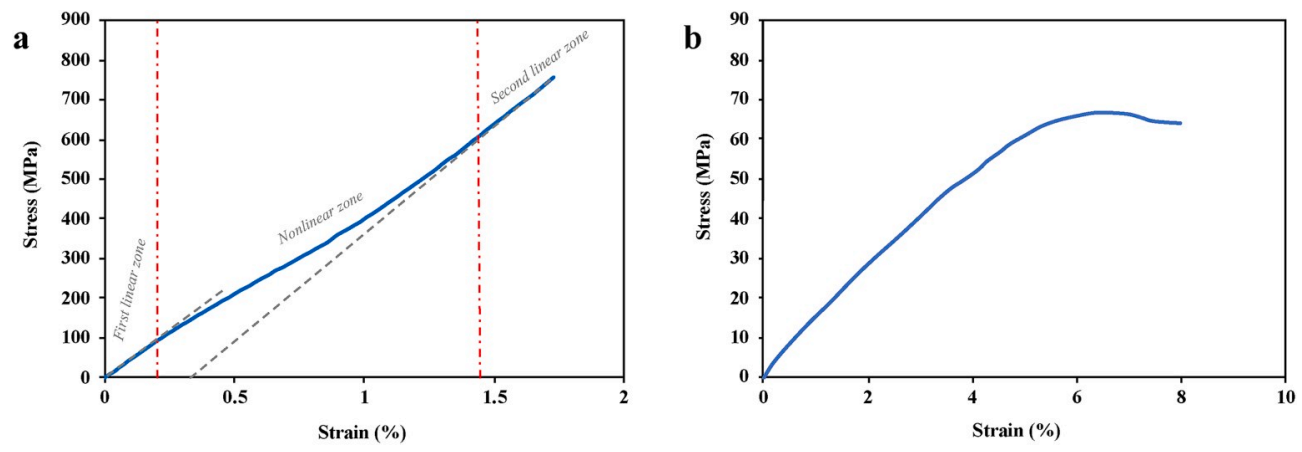

Fig. 3. Typical stress/strain curves of (a) elementary flax fiber (adapted from Ref. [25]) and (b) PLA matrix (adapted from Ref. [26]).

study to investigate the effect of the micro-friction between the cutting tool and each component of the composite. FE simulations are carried out using ABAQUS/Explicit software (version 6.11-2) [18]. Fig. 1 shows the transition from the real macroscopic scale of the experimental orthogonal cutting operation (Fig. 1(a)) to the finite element model developed at microscale with consideration of the fiber orientation (Fig. 1(b)).

The microscopic-based model consists of a bundle of four elementary flax fibers embedded in a natural polymer of polylactic-acid (PLA). As shown in Fig. 1(b), the interfaces between fibers and matrix are modeled with cohesive elements that have a thickness of $1 \mu \mathrm{m}$. Each elementary fiber has a diameter of $15 \mu \mathrm{m}$. The cutting tool is considered as an analytical rigid body where the movement is controlled by a reference point. Flax fibers are oriented with an angle " $\theta$ " from the cutting direction. A plane stress analysis, which is more suitable for FEM cutting of composites [15], is considered in this numerical investigation. Both flax fibers and PP matrix are meshed with 4-node bilinear plane stress quadrilateral elements (CPS4R) and $2 \mu \mathrm{m}$ of mesh size. Cohesive interfaces are meshed with a 4-node two-dimensional cohesive element (COH2D4) and $1 \mu \mathrm{m}$ of mesh size.

As for synthetic fiber composites, the thermal effect is not considered in this micromechanical study because the heat generation in orthogonal cutting requires a large cutting length $[19,20]$. The cutting length in the current model does not exceed $200 \mu \mathrm{m}$.

In the present model, five fiber orientations are considered $\left(\theta=0^{\circ}, \theta\right.$ $=25^{\circ}, \theta=45^{\circ}, \theta=65^{\circ}$, and $\theta=90^{\circ}$ ) as shown in Fig. 2. Only the positive fiber orientations range (from $0^{\circ}$ to $90^{\circ}$ with respect to the cutting direction) is considered because the negative fiber orientations range (from $90^{\circ}$ to $180^{\circ}$ with respect to cutting direction) lead to poor machinability of composites with a high delamination rate due to the torn-off of fibers [21].

For $\theta=0^{\circ}$, the cutting edge is considered to be firstly in contact with the matrix before getting into contact with the cross-section of an elementary flax fiber (Fig. 2(a)) and the removed material across the cutting depth is supposed to contain a bundle of three elementary flax fibers embedded in the PLA matrix.

\subsection{Micromechanical modeling}

Unlike synthetic fibers such as glass or carbon, the cellulosic structure of natural plant fibers generates an elastoplastic behavior that is due to the rearrangement of cellulosic microfibrils toward the fiber axis [22-25] as shown in Fig. 3(a). The PLA matrix generates an elastoplastic behavior [26] that is well-known for the thermoplastic polymers as shown in Fig. 3(b).

The cellulosic structure of natural plant fibers gives them an anisotropic behavior where the privileged direction is toward the fiber axis. The behavior of PLA is assumed isotropic. The considered values of elastic properties of both flax fibers and PLA are presented in Table 1. It's important to notice that the mechanical properties of flax fibers show a high variability [27]. Therefore, the mechanical inputs of Table 1
Table 1

Main mechanical properties used in the FE model.

\begin{tabular}{|c|c|c|c|c|c|}
\hline Material & Property & Direction & Value & Unit & Reference \\
\hline \multirow[t]{9}{*}{ Flax fibers } & \multirow[t]{3}{*}{ Stiffness } & $E_{11}$ & 50 & \multirow[t]{3}{*}{$\mathrm{GPa}$} & \multirow[t]{8}{*}[13,29]{} \\
\hline & & $E_{22}=E_{33}$ & 12 & & \\
\hline & & $\begin{array}{l}G_{12}=G_{13} \\
=G_{23}\end{array}$ & 3.4 & & \\
\hline & \multirow{5}{*}{$\begin{array}{l}\text { Poisson } \\
\text { ratio } \\
\text { Strength }\end{array}$} & $\nu_{12}$ & 0.178 & \multirow[t]{2}{*}{ - } & \\
\hline & & $\nu_{13}=\nu_{23}$ & 0.2 & & \\
\hline & & $S_{11}$ & 750 & \multirow[t]{3}{*}{$\mathrm{MPa}$} & \\
\hline & & $S_{22}=S_{33}$ & 150 & & \\
\hline & & $\begin{array}{l}S_{12}=S_{13}= \\
S_{23}\end{array}$ & 20 & & \\
\hline & $\begin{array}{l}\text { Fracture } \\
\text { energy }\end{array}$ & $G_{f}$ & 132 & $\begin{array}{l}\mathrm{KJ} / \\
\mathrm{m}^{2}\end{array}$ & $\begin{array}{l}\text { Calculated from } \\
\text { data of }[13,29]\end{array}$ \\
\hline \multirow[t]{4}{*}{ PLA matrix } & Stiffness & $E$ & 1.4 & $\mathrm{GPa}$ & \multirow[t]{4}{*}{ [26] } \\
\hline & $\begin{array}{l}\text { Poisson } \\
\text { ratio }\end{array}$ & $\nu$ & 0.35 & - & \\
\hline & Strength & $S$ & 64 & $\mathrm{MPa}$ & \\
\hline & $\begin{array}{l}\text { Fracture } \\
\text { energy }\end{array}$ & $G_{f}$ & 5 & $\begin{array}{l}\mathrm{KJ} / \\
\mathrm{m}^{2}\end{array}$ & \\
\hline \multirow[t]{3}{*}{$\begin{array}{l}\text { Cohesive } \\
\text { zone }\end{array}$} & Stiffness & $\begin{array}{l}K_{n n}=K_{s s}= \\
K_{t t} \\
K_{n s}=K_{n t}= \\
K_{s t}\end{array}$ & $\begin{array}{l}38 \\
0\end{array}$ & $\begin{array}{l}\mathrm{GPa} / \\
\mathrm{mm}\end{array}$ & $\begin{array}{l}\text { Calculated from } \\
\text { data of [36] }\end{array}$ \\
\hline & Strength & $t_{n}^{0}=t_{s}^{0}=t_{t}^{0}$ & 18 & $\mathrm{MPa}$ & {$[36,37]$} \\
\hline & $\begin{array}{l}\text { Fracture } \\
\text { energy }\end{array}$ & $G^{C}$ & 28 & $\mathrm{~J} / \mathrm{m}^{2}$ & \\
\hline
\end{tabular}

are chosen to be as closer as possible to those of flax fibers used in the experimental validation.

The longitudinal plastic behavior of flax fibers is implemented using 30 points on the yield stress versus plastic strain curve from Fig. 3(a) with a maximum yield stress of $750 \mathrm{MPa}$. For the PLA, the plastic behavior is also implemented using 20 points on the yield stress versus strain curve from Fig. 3(b).

To model the anisotropic plasticity-based failure for flax fibers, the Hill's potential function is used [28]. Hill's potential function is a simple extension of the Mises function, which can be expressed in terms of rectangular Cartesian stress components $\left(\sigma_{i j}\right)$ as following $[18,29]$ :

$f(\sigma)=\sqrt{F\left(\sigma_{22}-\sigma_{33}\right)^{2}+G\left(\sigma_{33}-\sigma_{11}\right)^{2}+H\left(\sigma_{11}-\sigma_{22}\right)^{2}+2 L \sigma_{23}^{2}+2 M \sigma_{31}^{2}+2 N \sigma_{12}^{2}}$

Where $F, G, H, L, M$ and $N$ are constants defined as following:

$F=\frac{\left(\sigma^{0}\right)^{2}}{2}\left(\frac{1}{\bar{\sigma}_{22}^{2}}+\frac{1}{\bar{\sigma}_{33}^{2}}+\frac{1}{\bar{\sigma}_{11}^{2}}\right)=\frac{1}{2}\left(\frac{1}{R_{22}^{2}}+\frac{1}{R_{33}^{2}}+\frac{1}{R_{11}^{2}}\right)$
$G=\frac{\left(\sigma^{0}\right)^{2}}{2}\left(\frac{1}{\bar{\sigma}_{33}^{2}}+\frac{1}{\bar{\sigma}_{11}^{2}}-\frac{1}{\bar{\sigma}_{22}^{2}}\right)=\frac{1}{2}\left(\frac{1}{R_{33}^{2}}+\frac{1}{R_{11}^{2}}-\frac{1}{R_{22}^{2}}\right)$ 
$H=\frac{\left(\sigma^{0}\right)^{2}}{2}\left(\frac{1}{\bar{\sigma}_{11}^{2}}+\frac{1}{\bar{\sigma}_{22}^{2}}-\frac{1}{\bar{\sigma}_{33}^{2}}\right)=\frac{1}{2}\left(\frac{1}{R_{11}^{2}}+\frac{1}{R_{22}^{2}}-\frac{1}{R_{33}^{2}}\right)$

$L=\frac{3}{2}\left(\frac{\tau^{0}}{\bar{\sigma}_{23}}\right)^{2}=\frac{3}{2 R_{23}^{2}}$

$M=\frac{3}{2}\left(\frac{\tau^{0}}{\bar{\sigma}_{13}}\right)^{2}=\frac{3}{2 R_{13}^{2}}$

$N=\frac{3}{2}\left(\frac{\tau^{0}}{\bar{\sigma}_{12}}\right)^{2}=\frac{3}{2 R_{12}^{2}}$

where each $\bar{\sigma}_{i j}$ is the measured yield stress value when $\sigma_{i j}$ is applied as the only nonzero stress component, $\tau^{0}=\frac{\sigma_{0}}{\sqrt{3}}$ where $\sigma_{0}$ is the reference yield stress which is set to be equal to $\sigma_{11}$ in this case; $R_{i j}$ are anisotropic yield stress ratios that are needed to implement the Hill's potential function in the FE model [18] and are defined as follows where the considered strength values are provided in Table 1:

$R_{11}=\frac{\bar{\sigma}_{11}}{\sigma^{0}}$

$R_{22}=\frac{\bar{\sigma}_{22}}{\sigma^{0}}$

$R_{33}=\frac{\bar{\sigma}_{33}}{\sigma^{0}}$

$R_{12}=\frac{\bar{\sigma}_{12}}{\tau^{0}}$

$R_{13}=\frac{\bar{\sigma}_{13}}{\tau^{0}}$

$R_{23}=\frac{\bar{\sigma}_{23}}{\tau^{0}}$

A ductile criterion [30] is considered to model the failure of both flax fibers and PLA. The ductile criterion is based on a fracture diagram which gives the equivalent plastic strain at fracture as a function of the stress state. The model assumes that the equivalent plastic strain at the onset of damage is a function of stress triaxiality and strain rate. The criterion for damage initiation is met when the following condition is satisfied [30]:

$\int_{0}^{\varepsilon_{e q}^{* *}} \frac{d \varepsilon_{e q}}{\varepsilon_{e q}^{* *}\left(\eta, \dot{\varepsilon}^{p l}\right)}=1$

where $\varepsilon_{e q}$ is the equivalent plastic strain, $\varepsilon_{e q}^{* * *}$ is the equivalent plastic strain at fracture, $\dot{\varepsilon}^{p l}$ is the equivalent plastic strain rate, and $\eta$ is stress triaxiality that can be calculated by the following equations [31]:

$\eta=\frac{\sigma_{m}}{\sigma_{e q}}$

Here $\sigma_{m}$ denotes the hydrostatic stress and $\sigma_{e q}$ is the Von Mises equivalent stress that can be calculated by the following equations:

$\sigma_{m}=\frac{\sigma_{11}+\sigma_{22}+\sigma_{33}}{3}$

$\sigma_{e q}=\sqrt{\frac{1}{2}\left[\left(\sigma_{11}-\sigma_{22}\right)^{2}+\left(\sigma_{22}-\sigma_{33}\right)^{2}+\left(\sigma_{33}-\sigma_{11}\right)^{2}+6\left(\sigma_{12}^{2}+\sigma_{23}^{2}+\sigma_{31}^{2}\right)\right]}$

As for the Hill's potential function, the stress triaxiality criterion is calculated using the strength values of Table 1 .

The damage evolution law describes the rate of degradation of the material stiffness once the corresponding initiation criterion has been reached. For elastoplastic materials, the damage evolution is carried out in two forms: softening of the yield stress and degradation of the elasticity [18]. The damage evolution law can be specified either in terms of fracture energy per unit area $\left(G_{f}\right)$ or the equivalent plastic displacement $\left(u^{p l}\right)$ which is related to the equivalent plastic strain $\left(\varepsilon^{p l}\right)$ by the following equation [32]:

$u^{p l}=L_{e} \varepsilon^{p l}$

$L_{e}$ is a characteristic length related to the element. The definition of the characteristic length depends on the element geometry and formulation: it is a typical length of a line across an element for a first-order element, and it is half of the same typical length for a second-order element [18].

The equivalent plastic displacement at failure is computed following the equation (19) where $\sigma_{y 0}$ is the value of the yield strength [18,32].

$u_{f}^{p l}=\frac{2 G_{f}}{\sigma_{y 0}}$

In the FE model, the damage evolution is modeled using the fracture energy per unit area $\left(G_{f}\right)$. This parameter is available in literature for PLA. For flax fibers, the value used for $G_{f}$ is estimated based on the Griffith theory for ductile materials [33] using the equation (20) where $\sigma_{f}$ is the tensile strength, $E$ is the Young modulus and $a$ is the cracking length that has been assumed to be equal to the elementary fiber diameter.

$G_{f}=\frac{\sigma_{f}^{2} \pi a}{4 E}$

Interfaces are modeled using the cohesive zone model (CZM). The elastic behavior of the CZM is modeled using a linear elastic tractionseparation behavior. It assumes initially linear elastic behavior followed by the initiation and evolution of damage. The elastic behavior is written in terms of an elastic constitutive matrix that relates the nominal stresses to the nominal strains across the interface following the equation [18]:

$\left\{\begin{array}{l}t_{n} \\ t_{s} \\ t_{t}\end{array}\right\}=\left[\begin{array}{lll}E_{n n} & E_{n s} & E_{n t} \\ E_{n s} & E_{s s} & E_{s t} \\ E_{n t} & E_{s t} & E_{t t}\end{array}\right]\left\{\begin{array}{l}\varepsilon_{n} \\ \varepsilon_{s} \\ \varepsilon_{t}\end{array}\right\}$

Where $t_{n}, t_{s}$ and $t_{t}$ are the nominal stresses in the normal, shear and tangential directions, respectively. $E_{i j}$ are the components of the elasticity matrix. $\varepsilon_{n}, \varepsilon_{s}$ and $\varepsilon_{t}$ are the nominal strains in the normal, shear and tangential directions, respectively. The corresponding separations are denoted by $\delta_{n}, \delta_{s}$ and $\delta_{t}$ and are defined as following, where $T_{0}$ is the initial thickness of the cohesive element [18]:

$\varepsilon_{n}=\frac{\delta_{n}}{T_{0}}$

$\varepsilon_{s}=\frac{\delta_{s}}{T_{0}}$

$\varepsilon_{t}=\frac{\delta_{t}}{T_{0}}$

In Abaqus software, the penalty stiffness parameter $\left(K_{i j}\right)$ is implemented to model the rigidity of the cohesive zone [34,35] and it is defined by the following equation:

$\left\{\begin{array}{l}t_{n} \\ t_{s} \\ t_{t}\end{array}\right\}=\left[\begin{array}{lll}K_{n n} & K_{n s} & K_{n t} \\ K_{n s} & K_{s s} & K_{s t} \\ K_{n t} & K_{s t} & K_{t t}\end{array}\right]\left\{\begin{array}{l}\delta_{n} \\ \delta_{s} \\ \delta_{t}\end{array}\right\}$

Damage of cohesive zones is assumed to initiate when a quadratic interaction function involving the nominal stress ratios reaches a value of one. This criterion can be represented as following [18,29]:

$\left(\frac{\left\langle t_{n}\right\rangle}{t_{n}^{0}}\right)^{2}+\left(\frac{t_{s}}{t_{s}^{0}}\right)^{2}+\left(\frac{t_{t}}{t_{t}^{0}}\right)^{2}=1$ 


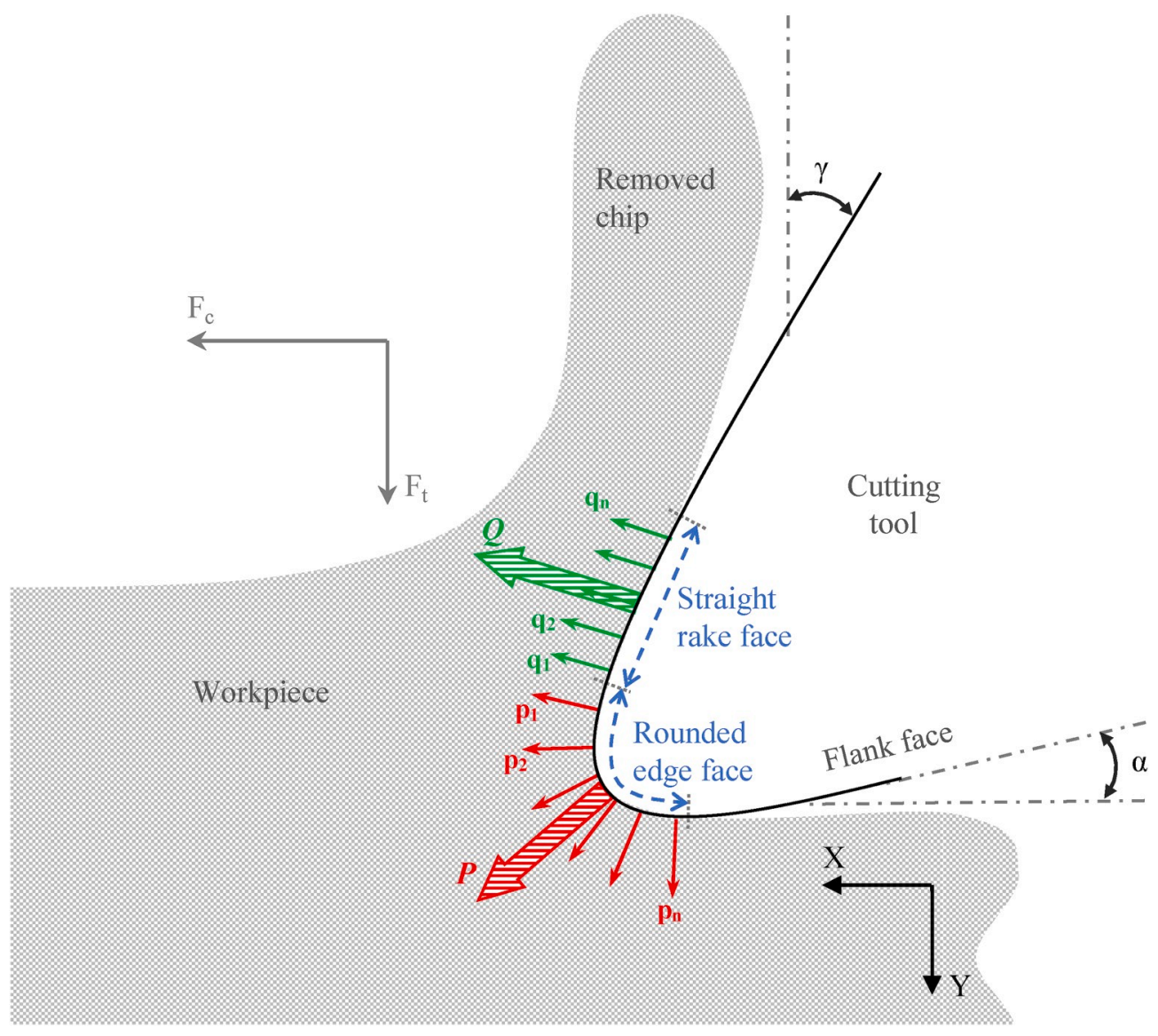

Fig. 4. Schematic depiction of orthogonal cutting process with a rounded cutting tool edge.

$t_{n}^{0}, t_{s}^{0}$ and $t_{t}^{0}$ are the peak values of the nominal stress components in the normal, shear and tangential directions, respectively. The symbol \langle\rangle in the equation (26) represents the Macaulay bracket which is used to signify that a pure compressive deformation or stress state does not initiate damage [18].

\subsection{Friction modeling}

Friction is one of the most important phenomena that should be considered to model the machining operations. The significance of friction in machining is due to the high stresses and velocities generated during the tool-material contact. However, modeling friction in machining is a complicated task because it should consider different factors related to the contact geometry, especially the geometrical parameters of the cutting tool edge such as the rake angle, the clearance angle and the cutting edge radius.

In metal cutting, it is usual to consider the tool as infinitely sharp, so the tool-material contact is along a perfect straight rake face [38]. According to that assumption, and if the tool has not been subjected to wear (fresh tool), the whole pressure at the cutting contact has a constant direction and can be summed up in one resultant force in the same direction. Therefore, the cutting friction coefficient is constant along the tool face and can be calculated using the following equation derived from Merchant model [38].

$\mu=\frac{F_{t}+F_{c} \tan (\gamma)}{F_{c}-F_{t} \tan (\gamma)}$

Where $F_{c}$ is the cutting force (in the feed direction), $F_{t}$ is the thrust force (normal to the feed direction), and $\gamma$ is the rake angle of the tool. If the process parameters (cutting speed and depth) are kept constant, the friction coefficient will depend highly on the rake angle of the tool.

Nevertheless, the fact that the cutting tools have a rounded edge cannot be ignored for machining of fiber composites because this geometrical parameter has a significant impact of the cutting behavior of fibers $[10,39,40]$, especially when machining natural fiber composites that are highly sensitive to the small variations of the cutting edge radius [10]. In the following, the cutting friction is discussed by considering the rounded cutting edge.

As illustrated in Fig. 4, when considering a fresh tool with a rounded edge, two contact regions can be defined. The first contact region is between the removed chip and the straight rake face. The tool-material contact in this region is similar to that described with Merchant model [38]. The resultant contact force ( $Q$ in Fig. 4) is obtained by summing the infinitesimal forces along the straight rake face $\left(\mathrm{q}_{1}, \mathrm{q}_{2}, \ldots, \mathrm{q}_{\mathrm{n}}\right.$ in figure) that are in the same direction. Stick and slip conditions of friction are assumed in this contact region [41].

The second region is between the uncut chip and the rounded edge face. The infinitesimal contact force components $\left(\mathrm{p}_{1}, \mathrm{p}_{2}, \ldots, \mathrm{p}_{\mathrm{n}}\right.$ in Fig. 4) change the direction according to the cutting edge curvature. Therefore, the resultant contact force ( $P$ in Fig. 4 ) along the rounded edge face depends on the cutting edge radius [42]. In this contact region, when the chip slides along the tool face, the material in front of the rounded edge face is ploughed and pressed into the chip surface. Ploughing condition of friction are thus assumed in this contact region [42]. The cutting friction coefficient in this case is expressed as following:

$\mu=\frac{\left(F_{t}-P_{y}\right)+\left(F_{c}-P_{x}\right) \tan (\gamma)}{\left(F_{c}-P_{x}\right)-\left(F_{t}-P_{y}\right) \tan (\gamma)}$

Where $P_{x}$ and $P_{y}$ are the components of the ploughing force $P$ in $\mathrm{X}$ and $\mathrm{Y}$ directions, respectively. 
$\mathbf{a}$

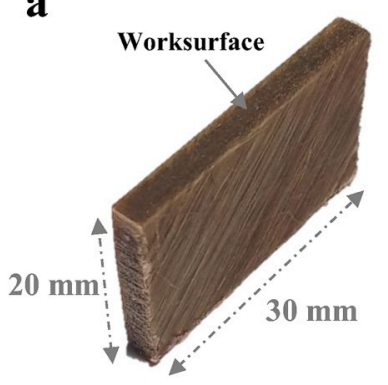

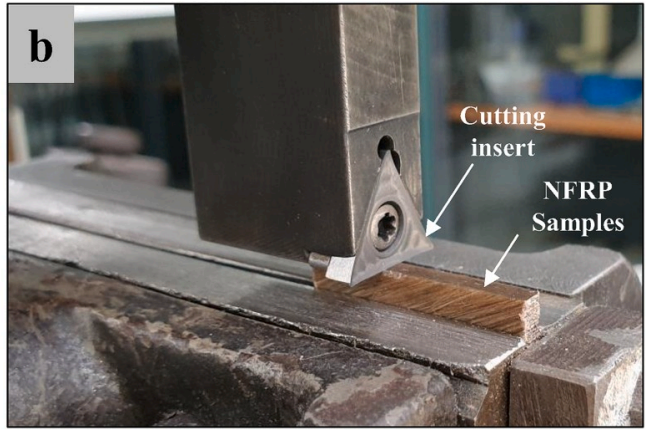

Fig. 5. (a) Image of flax/PLA samples, (b) Image of the experimental orthogonal cutting setup.

If the hypothesis of sharp cutting edge is assumed, the ploughing force $P$ is neglected and, then, the equation (27) will be equivalent to the equation (28).

It is important to note that, if the cutting tool is suffered from wear, a third contact region between the machined surface and the flank tool face will be activated and will influence the frictional behavior of the cutting operation [41].

To simulate the orthogonal cutting friction with ABAQUS/CAE software in the micromechanical FE model, a penalty contact method is considered to define each contact interaction [18]. This method is based on Coulomb friction law to control the frictional contacts between the cutting tool and the composite. Coulomb friction law assumes that relative motion between the tool and the composite occurs at the contact point when the equivalent shear stress along the tool-material interface $\left(\tau_{f}\right)$ is more than or equal to the critical friction stress as follows $[18,43]$ :

$\tau_{f} \geq \tau_{c r i t}=\mu n_{p}$

Where $\mu$ is the friction coefficient and $n_{p}$ is the normal pressure at the same point.

Therefore, the notion of friction in the FE model is based on the interaction between the nodes of the too surfaces in contact. Since the developed model is performed at microscale, the friction coefficient considered in the FE model is that generated by the infinitesimal contact forces shown in Fig. 4 (i.e. $\{\mathrm{q} 1-\mathrm{qn}\}$ for the straight rake face and $\{\mathrm{p} 1-$ pn\} for the rounded edge face) at each contact node. Thus, the friction coefficient needed for the micromechanical model should be the local friction coefficient at each point of the cutting contact. This local friction will be termed as micro-friction.

The concept of micro-friction is resulting from the scale effect that is related to the anisotropy of the contact between the NFRP and the Cutting tool. Since the cutting edge radius is microscopic $(\sim 12 \mu \mathrm{m})$, the aim is to define the local friction at the contact tool edge/flax fibers and the contact tool edge/polymer matrix. Thus, the micromechanical model will differentiate two contact pairs with the cutting tool because elementary flax fibers and PLA matrix are modeled separately. Consequently, two micro-friction parameters will be considered in this study:

- The micro-friction coefficient of the contact between the cutting tool and flax fibers: $\mu_{\mathrm{f}}$

- The micro-friction coefficient of the contact between the cutting tool and PLA matrix: $\mu_{\mathrm{m}}$

As shown in Section 1, $\mu_{\mathrm{f}}$ is found to be equal to 0.5 for a Diamond tool and 0.2 for a Sapphire tool, while $\mu_{\mathrm{m}}$ is found to be 0.4 for a Diamond tool and 0.2 for a Sapphire tool $[16,17]$. A high variability of friction coefficient is then induced by the material tool at both flax fibers and PLA matrix and, consequently, these friction coefficient values cannot be used to model the frictional contact of the orthogonal cutting experiments that are performed with a carbide cutting tool. The micro-friction coefficients $\left(\mu_{\mathrm{f}}\right.$ and $\mu_{\mathrm{m}}$ ) related to the contact with a
Table 2

Cutting parameters considered for both experimental tests and numerical modeling.

\begin{tabular}{llll}
\hline & Parameter & Value & Unit \\
\hline Tool geometry & Rake angle $(\gamma)$ & 20 & Degree $\left(^{\circ}\right)$ \\
& Clearance angle $(\alpha)$ & 7 & Degree $\left(^{\circ}\right)$ \\
& Edge radius $\left(r_{\varepsilon}\right)$ & 12 & $\mu \mathrm{m}$ \\
Cutting parameters & Depth of cut $\left(a_{p}\right)$ & 100 & $\mu \mathrm{m}$ \\
& Cutting speed $\left(V_{c}\right)$ & 50 & $\mathrm{~m} / \mathrm{min}$ \\
Material parameters & Fiber orientation $(\theta)$ & $0 / 25 / 45 / 65 / 90$ & Degree $\left(^{\circ}\right)$ \\
\hline
\end{tabular}

carbide material are unknown and are not available in literature. Therefore, a large range of micro-friction coefficient values (from 0.1 to 0.5 ) is investigated in the numerical model in order to determine which values of micro-friction coefficients $\left(\mu_{\mathrm{f}}\right.$ and $\mu_{\mathrm{m}}$ ) will be suitable to reproduce the experimental outputs.

It can also be noticed that, depending on the tool material, the microfriction coefficient on flax fibers and polymer matrix $\left(\mu_{\mathrm{f}}\right.$ and $\left.\mu_{\mathrm{m}}\right)$ can be similar or different. Since the micro-frictional behavior of carbide material tool is unknown, two hypotheses are investigated in this study:

- Hypothesis of isotropic micro-friction: the carbide cutting tool generates similar micro-friction coefficient on both flax fibers and polymer matrix: $\mu_{\mathrm{f}}=\mu_{\mathrm{m}}$

- Hypothesis of anisotropic micro-friction: the carbide cutting tool generates dissimilar micro-friction coefficient on flax fibers and polymer matrix: $\mu_{\mathrm{f}} \neq \mu_{\mathrm{m}}$

\section{Experimental validation setup}

The green composite samples used in this study (Fig. 5(a)) are provided by "Kairos Biocomposites - France". The samples are manufactured by stacking 10 layers of a non-woven flax fabric and 11 layers of PLA thin films using the thermo-compression technique.

Orthogonal cutting tests are made on a shaper machine (GSP - EL 136) with a carbide cutting insert (Sandvik - TCGX 16 T3 04 - AL H10) as shown in Fig. 5(b). The machining forces are acquired using a piezoelectric dynamometer (Kistler - 9255B). The machined surfaces are then observed at microscale using the scanning electron microscope (SEM) at low vacuum mode (JEOL - 5510LV). To highlight the in-situ chip formation mechanisms during cutting, a fast-camera (FASTCAM SA5 CCD) was used for recording optical frames at an acquisition rate of 20,000 fps. 3D topographic surface variations were measured by a threedimensional optical interferometer (WYKO 3300NT). Table 2 summarizes the machining parameters used for both experimental tests and numerical modeling. For the experimental part, each cutting configuration is tested three times to assure the repeatability. Thus, the final outputs from the orthogonal cutting experiments are presented as the mean value of these three repeated tests. Measurement errors are considered as the average of the absolute deviations of data repeatability 

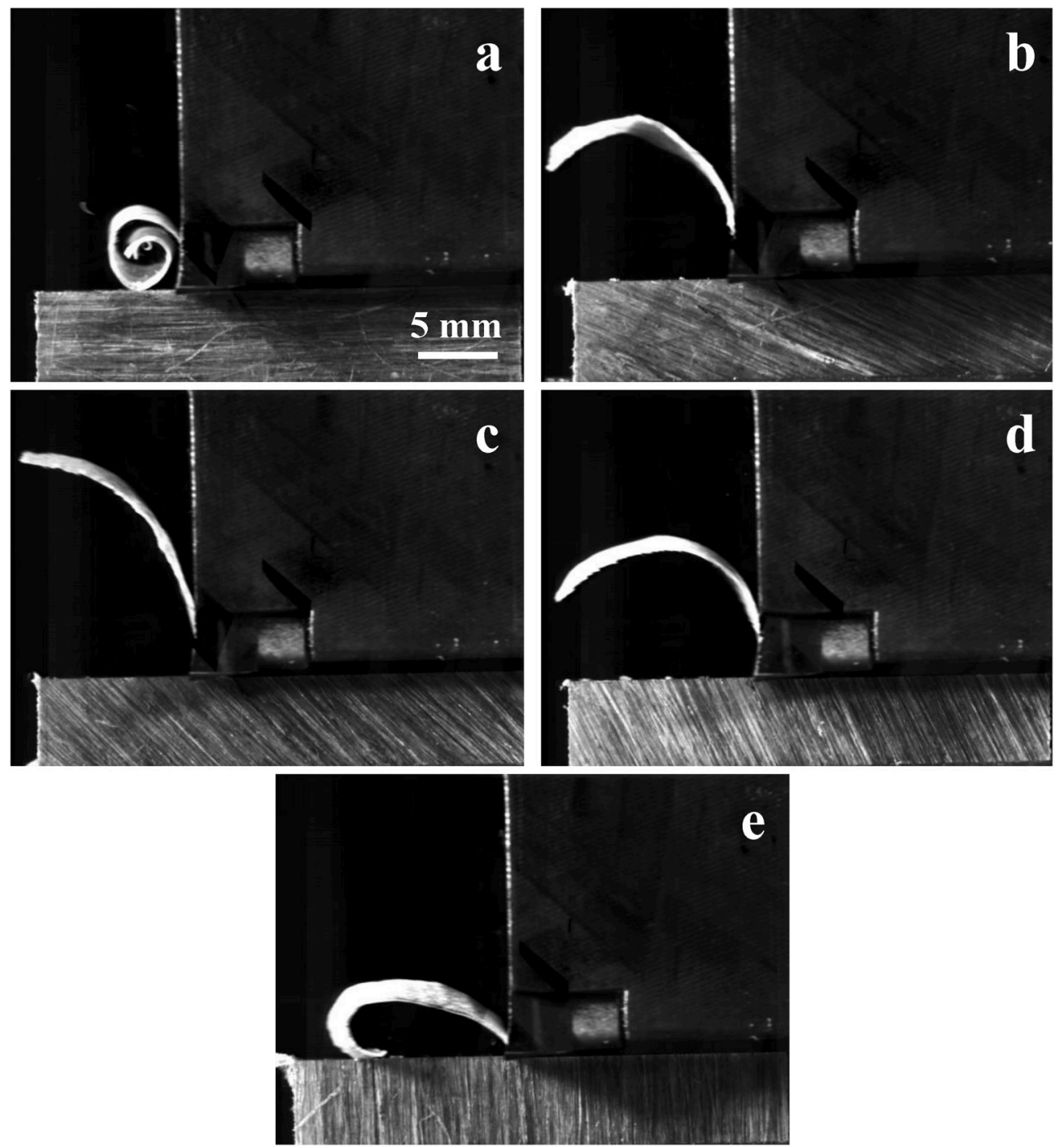

Fig. 6. Fast-cam images of the chip formation during orthogonal cutting of flax/PLA composites at the different considered fiber orientations. (a) $\theta=0^{\circ}$, (b) $\theta=25^{\circ}$, (c) $\theta=45^{\circ}$, (d) $\theta=65^{\circ}$, and (e) $\theta=90^{\circ}$.

tests from their mean.

\section{Results and discussion}

\subsection{Effect of flax fiber orientation on the experimental chip formation}

Fig. 6 shows that the removed chip remains continuous regardless of the fiber orientation. However, flax fiber orientation has an obvious effect on the shape of the removed chip, typically the chip curling. The cutting of flax/PLA composites with a fiber orientation of $\theta=0^{\circ}$ generates the highest curled chip. Then, the chip curling is reduced when increasing the fiber orientation up to $\theta=45^{\circ}$, and it is increased when increasing the fiber orientation from $\theta=45^{\circ}$ to $\theta=90^{\circ}$.

The fact that the chip remain continuous for all the cutting configurations reflects the ductile behavior of flax/PLA composites during the machining operation. This behavior is induced by the combination of the well-known ductile properties of thermoplastic polymers and the elastovisco-plastic behavior of natural flax fibers [23]. The ductile failure mode of this kind of thermoplastic composites avoids the brittle fracture of the chip during its formation [10].

\subsection{Experimental and numerical machining behaviors of flax $/ P L A$ composites}

Fig. 7 shows the experimental SEM observations of the machined surfaces of flax/PLA composites at the different considered fiber orientations. It can be seen that flax/PLA composites show globally an efficient machinability. Indeed, by comparing the microscopic observations of this study and the results of our previous work with flax/polypropylene (PP) samples $[10,13]$, the fibers shearing of flax/PLA is more efficient with no significant debonding zones. These latter were more important when machining flax/PP and are caused by both the transverse deformation of fibers and the failure of the interfaces $[10,13]$. The main factors that could be behind this behavior are the mechanical and the adhesive properties of the polymer matrices. In fact, when comparing the stress/strain curves of PLA given in Fig. 3(b) and that of PP given in Ref. [13], it is evident that PP matrix exhibits a higher plasticity than that of PLA. Therefore, flax fibers in PP matrix have lower contact stiffness than that of flax fibers in PLA matrix during the cutting operation. The low contact stiffness engenders a high deformation of flax fibers toward the cutting direction which causes an ineffective fiber shearing and, hence, the failure of the interfaces. In the current study, the higher stiffness of PLA matrix, comparing to PP matrix, encounters these issues. 

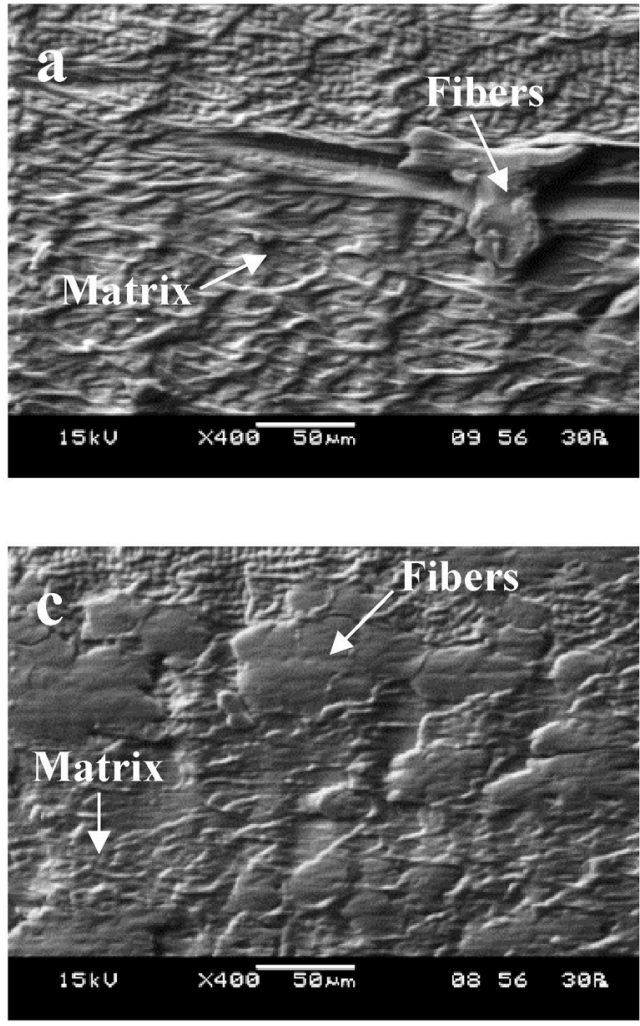
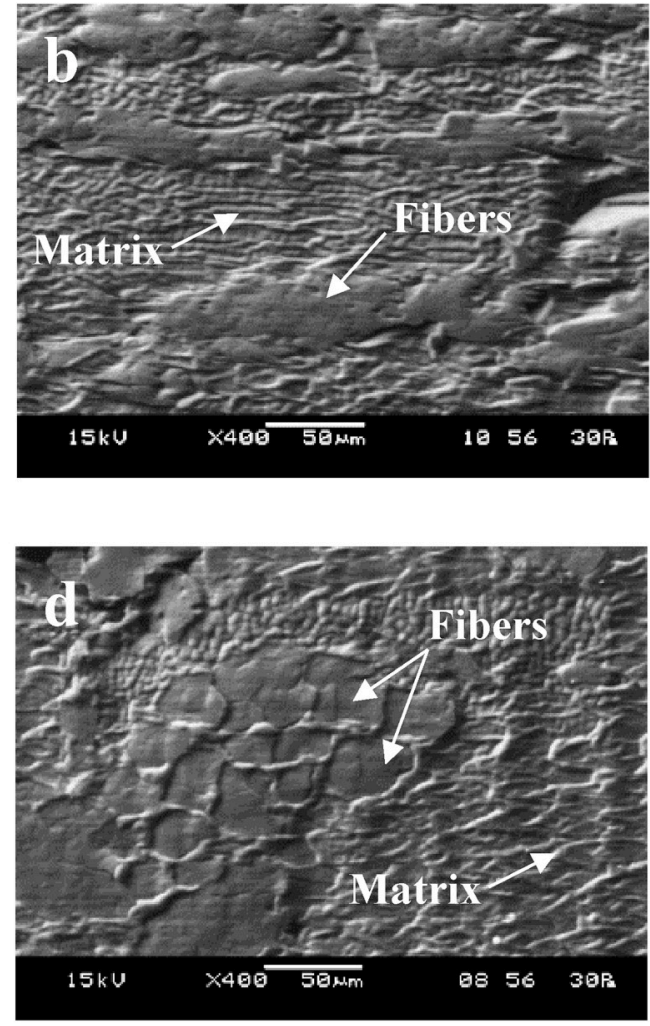

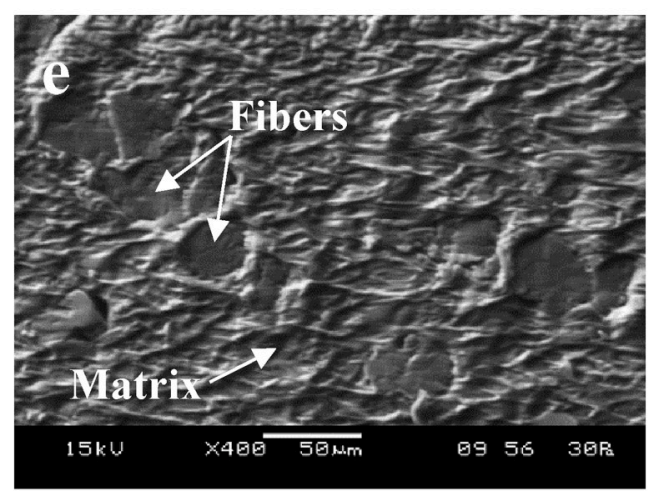

Fig. 7. Typical SEM images of machined surfaces of flax/PLA composites at the different considered fiber orientations. (a) $\theta=0^{\circ}$, (b) $\theta=25^{\circ}$, (c) $\theta=45^{\circ}$, (d) $\theta=$ $65^{\circ}$, and (e) $\theta=90^{\circ}$.

It can also be seen that the machined surface with fiber orientation of $\theta=65^{\circ}$ (Fig. 7(d)) shows the best fiber shearing since the cross section of fibers are more obvious than that of the other configurations. This demonstrates that the fiber orientation $\theta=65^{\circ}$ provides the highest contact stiffness during the cutting operation which favors the shearing and avoids high plastic deformation. For the fiber orientation $\theta=0^{\circ}$, some detached and torn-off fibers are detected as shown in Fig. 7(a). These phenomena are especially due to the contact location between the cutting edge and the fibers. The fibers oriented toward the cutting direction may be sheared, detached or torn-off regarding the location of the cutting edge on the cross-section of each elementary fiber on the fiber bundle.

Fig. 8 shows the numerical cutting behavior of the flax/PLA composite obtained by the 2D FE micromechanical model. The numerical cutting behavior of flax fibers are similar to that shown in the experimental SEM observations. Flax fibers are efficiently sheared without high transverse deformations or high interfaces failure. The micromechanical model shows that the orientations $\theta=65^{\circ}$ generates less subsurface damages and less interfaces failure. This finding is also noticed in the SEM observations of Fig. 7(d) where the fibers shape is more obvious than the other configurations. The fact that flax fiber shapes are still obvious in the microscopic observations means that the fibers have not been significantly deformed and damaged during the cutting operation. For $\theta=0^{\circ}$, the FE model does not reproduce the detachment or the torn-off of fibers because the cutting edge has been placed on the middle of the cross section of the fiber 2 in Fig. 8(a). The resulting fiber behavior should be shearing rather than detachment or torn-off.

\subsection{Effect of micro-friction coefficient on numerical machining forces}

\subsubsection{Hypothesis of isotropic micro-friction}

Fig. 9 presents the results of numerical cutting and thrust forces at different isotropic micro-friction values in order to compare with the experimental outputs. From the graph of cutting forces in Fig. 9(a), it can be seen that the numerical cutting forces correspond to the experimental results in terms of trend and magnitude. Moreover, the variation of the micro-friction coefficient has not a significant effect on the numerical 

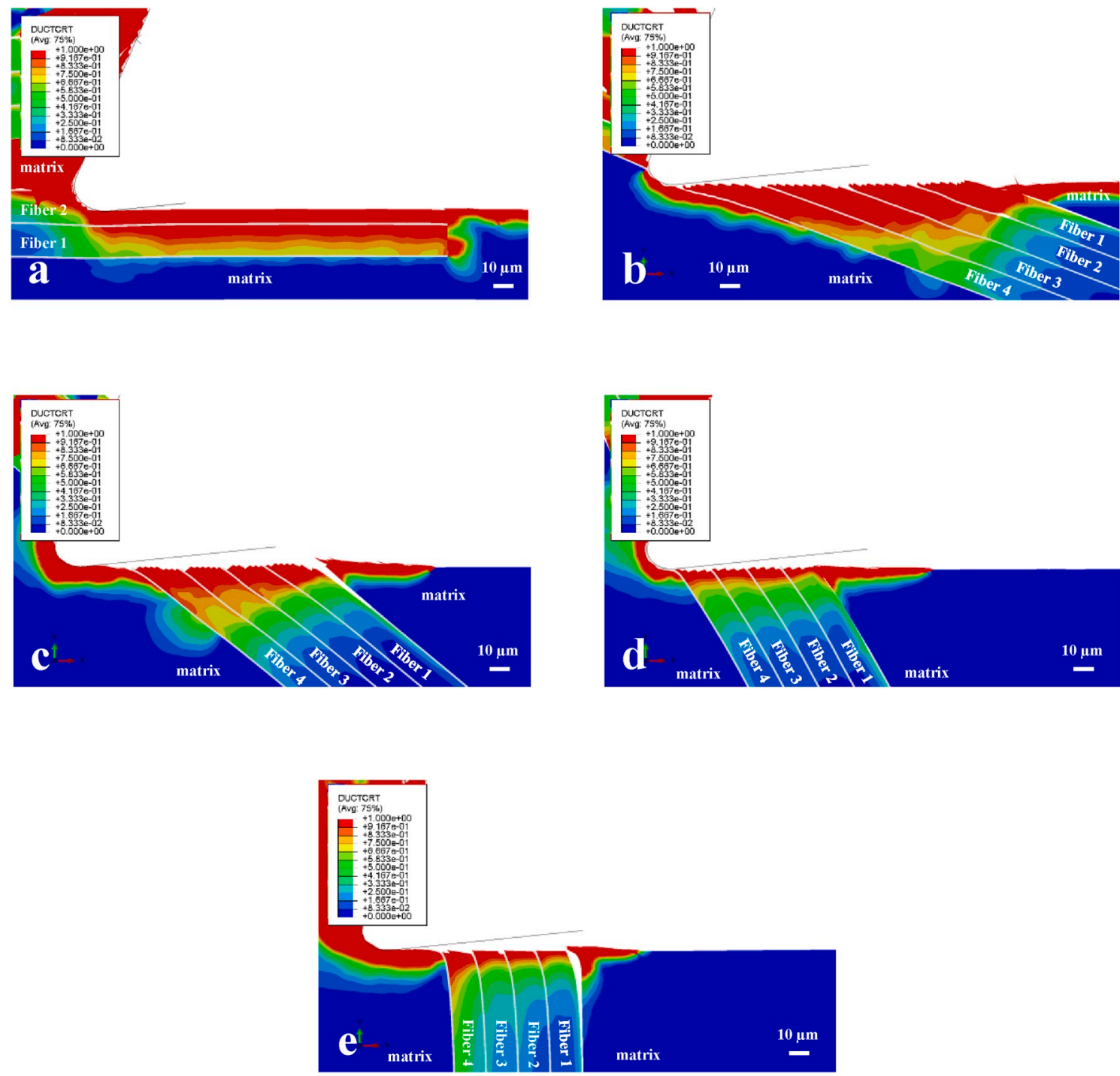

Fig. 8. FE model showing the ductile criterion map of the orthogonal cutting of flax/PLA composite at the different considered fiber orientations. (a) $\theta=0^{\circ}$, (b) $\theta=$ $25^{\circ}$, (c) $\theta=45^{\circ}$, (d) $\theta=65^{\circ}$, and (e) $\theta=90^{\circ}$.
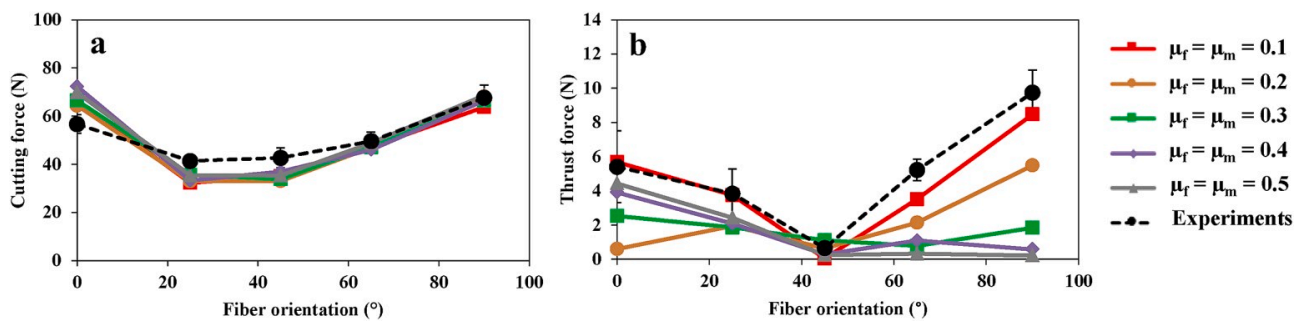

Fig. 9. Comparison between experimental and numerical machining forces at different values of isotropic micro-friction. (a) cutting forces, (b) thrust forces.

cutting force results. For the thrust forces presented in Fig. 9(b), the numerical results show a high variation in function of the isotropic micro-friction. At $\theta=90^{\circ}$ and $\theta=65^{\circ}$, the numerical thrust force decreases significantly by the increase of the micro-friction from 0.1 to 0.5 to be far from the experimental value. This could explain the difference in magnitude of the thrust forces observed in Ref. [13] since the micro-frictions that were used are $\mu_{\mathrm{f}}=0.5$ and $\mu_{\mathrm{m}}=0.4$. At $\theta=45^{\circ}$, there is no significant effect of the micro-friction on the thrust force. On the other hand, the lowest value of the isotropic micro-friction $\left(\mu_{\mathrm{f}}=\mu_{\mathrm{m}}\right.$ $=0.1$ ) generates the highest values of the numerical thrust force in the case of $\theta=0^{\circ}$ and $\theta=25^{\circ}$. Beyond this lowest micro-friction value, the numerical thrust force increases by increasing the micro-friction at $\theta=$ $0^{\circ}$ while the effect of the micro-friction is insignificant at $\theta=25^{\circ}$. Consequently, the numerical thrust forces have a good correlation with the experimental results when the value of the isotropic micro-friction is equal to 0.1 .

\subsubsection{Hypothesis of anisotropic micro-friction}

Fig. 10 shows that the numerical cutting forces have a similar behavior as the hypothesis of an isotropic micro-friction presented in 

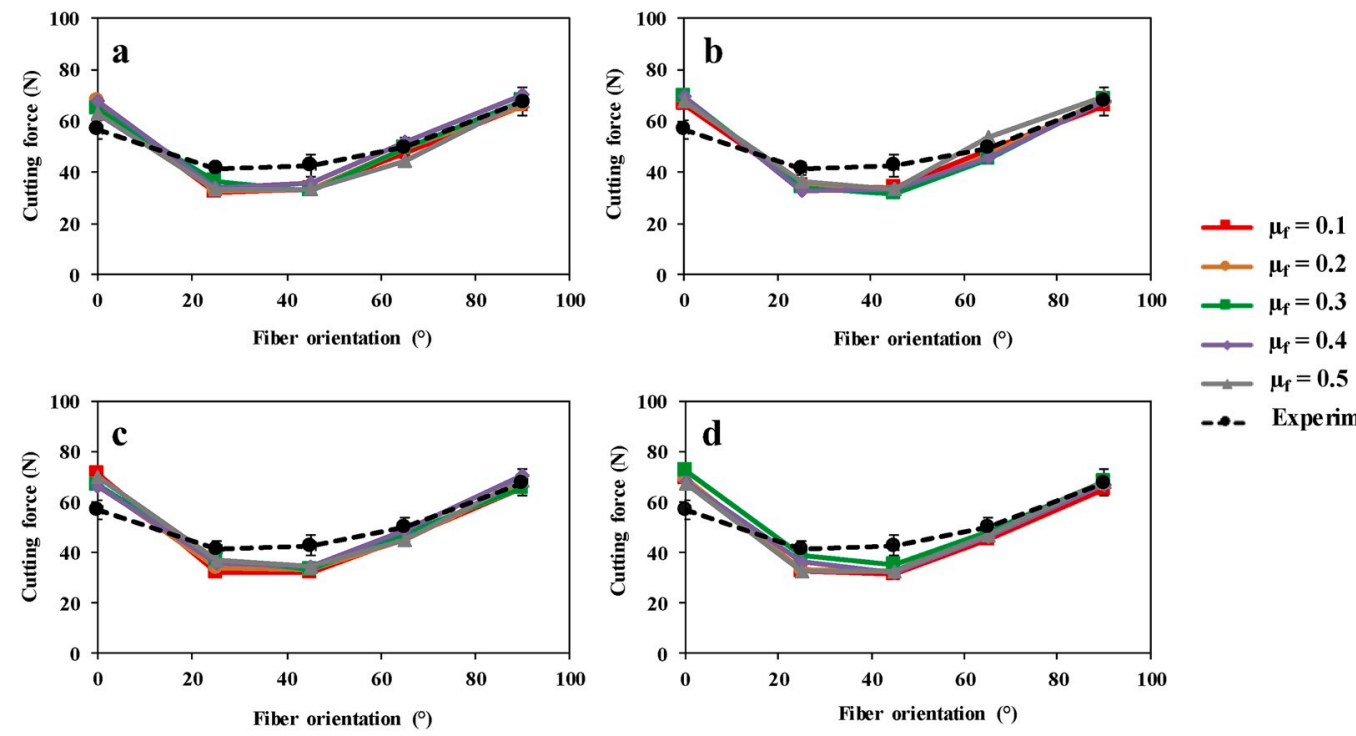

-๑- Experiments

Fig. 10. Comparison between experimental and numerical cutting forces at different values of anisotropic micro-friction. (a) $\mu \mathrm{m}=0.1,(\mathrm{~b}) \mu \mathrm{m}=0.2$, (c) $\mu \mathrm{m}=0.3$, and (d) $\mu \mathrm{m}=0.4$.
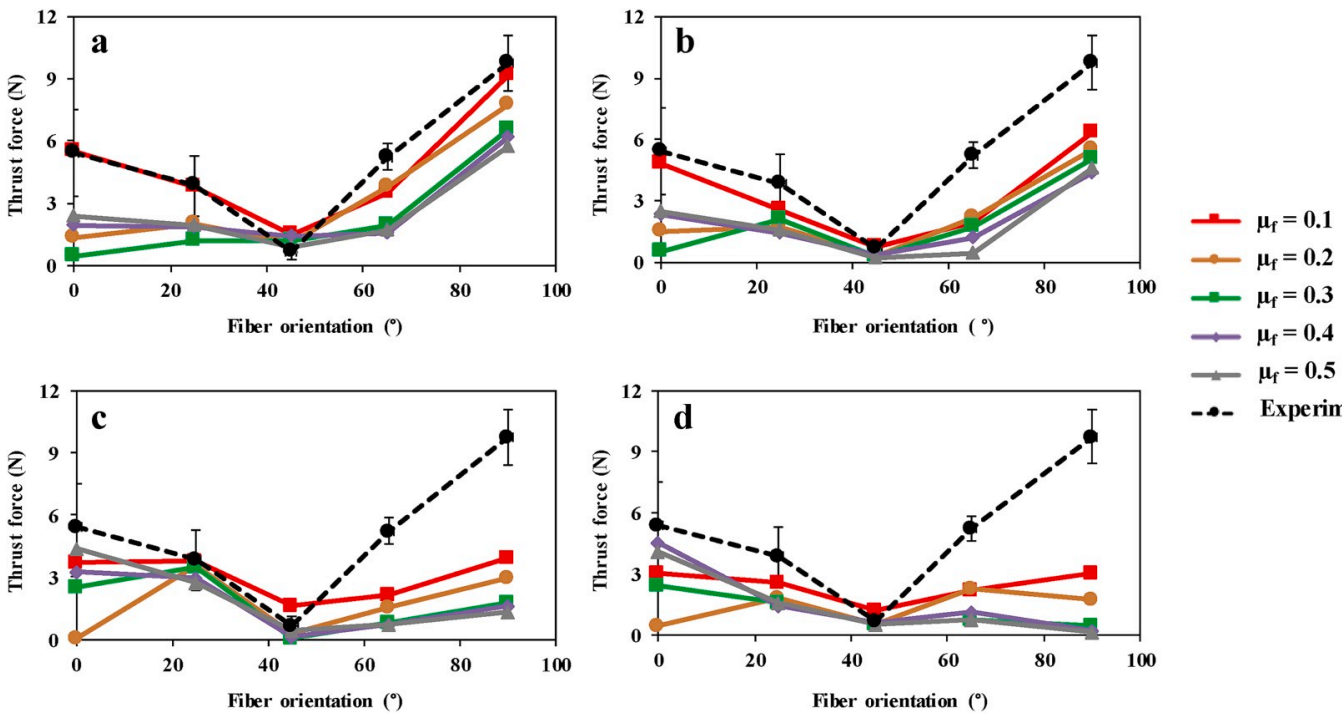

_._ Experiments

Fig. 11. Comparison between experimental and numerical thrust forces at different values of anisotropic micro-friction. (a) $\mu \mathrm{m}=0.1$, (b) $\mu \mathrm{m}=0.2$, (c) $\mu \mathrm{m}=0.3$, and (d) $\mu \mathrm{m}=0.4$.

Fig. 9(a). The micro-friction between the cutting tool and flax fibers does not affect the numerical cutting forces. However, the value 0.1 of microfriction between the cutting tool and the PLA matrix leads to decrease slightly the numerical cutting forces at $\theta=0^{\circ}$ and, then, to get a better fit with the experimental value as shown in Fig. 10(a).

For the numerical thrust forces, Fig. 11 shows that, at each value of $\mu_{\mathrm{m}}$, the numerical results present a high variability in function of $\mu_{\mathrm{f}}$ as the hypothesis of an isotropic micro-friction presented in Fig. 9(b). Moreover, increasing $\mu_{\mathrm{m}}$ leads to an increase of the divergence between the numerical and the experimental results. Fig. 11(a) reveals that a good agreement between the numerical and the experimental results for thrust forces is reached for an isotropic micro-friction between the cutting tool and the NFRP components where $\mu_{\mathrm{f}}=\mu_{\mathrm{m}}=0.1$.

\subsection{Effect of fiber orientation on the experimental machined surface topography}

To qualify the effect of fiber orientation on the machinability of flax/
PLA composites, optical interferometer has been used to capture the machined surface topography. As explained in section 1, The topographic image size should correspond to the considered fibrous structure size in order to be on the relevant scale for an efficient topographic analysis. The fibrous structure size in the case of the considered flax/PLA composites are continuous unidirectional bundles of flax fibers. The average diameter of the flax fiber bundles in flax/PLA composites is about $150^{ \pm 50} \mu \mathrm{m}$. The objective of the interferometer has been adapted to be as close as possible to this scale range. Therefore, an objective with a magnification of $\times 20$ is used to get topographic images of $153 \times 204$ $\mu \mathrm{m}^{2}$. The quantification of these measurements with the arithmetic mean of the surface roughness (Sa) is given in Fig. 12.

The cutting behavior of flax fibers within PLA matrix shown in Section 4.2 is accurately quantified by the topographic measurements of Fig. 12. Indeed, the machined surfaces with $\theta=65^{\circ}$ generate the lowest surface roughness thanks to the efficient shearing of flax fibers as clearly shown in the SEM images of Fig. 7. The FE numerical model predicts the same finding where the cutting configuration with $\theta=65^{\circ}$ produces less 


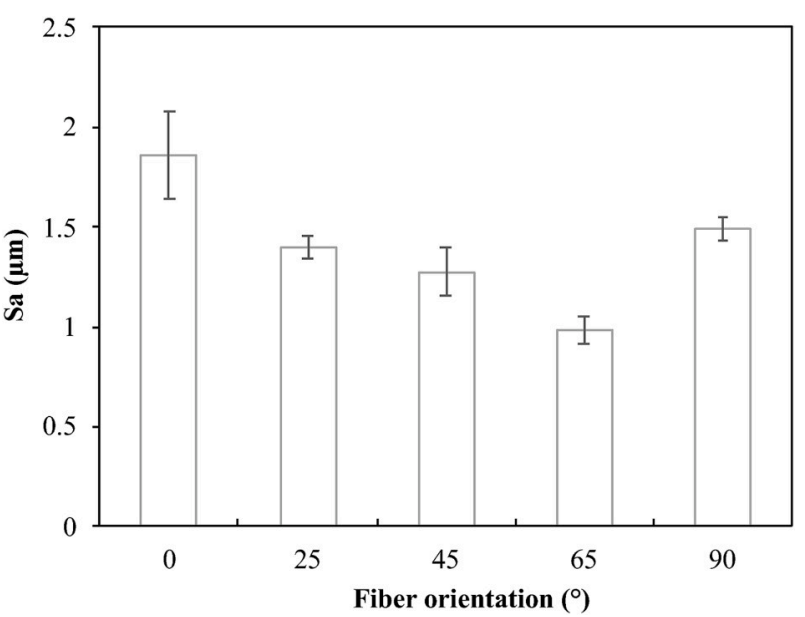

Fig. 12. Arithmetic surface roughness of machined surfaces of flax/PLA composites at the different considered fiber orientation.

damages in fibers without significant debonding in the interfaces as shown in Fig. 8(d). On the other hand, the random cutting behavior of flax fibers at $\theta=0^{\circ}$ induces high irregularities on the topographic signals which induces the highest surface roughness.

\section{Conclusions}

In this paper, a 2D finite element model for machining of natural fiber composites at microscale has been investigated and optimized in order to reproduce efficiently the machining forces. The optimization approach was based on the investigation of the micro-friction between the cutting tool edge and the two main components of the flax/PLA composite. The following conclusions can be drawn:

- The numerical cutting forces provided by the micromechanical model correspond to the experimental results and are not affected by the variation of the micro-friction between the tool and the composite phases.

- The numerical thrust forces provided by the micromechanical model are significantly affected by the micro-friction between the tool and the composite phases.

- The micromechanical model shows that an isotropic micro-friction coefficient of 0.1 between the carbide cutting insert and the composite phases allows a good correlation of the thrust forces with the experimental results.

- The micromechanical model can reproduce qualitatively the cutting behavior of natural fibers at different fiber orientations.

- Based on the FE model and the experimental results, the cutting configuration with a fiber orientation of $65^{\circ}$, with respect to the cutting direction, offers the best surface quality with an efficient shearing of flax fibers and the lowest surface roughness.

\section{Declaration of competing interest}

The authors declare that they have no known competing financial interests or personal relationships that could have appeared to influence the work reported in this paper.

\section{CRediT authorship contribution statement}

Faissal Chegdani: Conceptualization, Methodology, Writing - original draft. Mohamed El Mansori: Conceptualization, Supervision, Writing - review \& editing. Amen-Allah Chebbi: Investigation, Validation.

\section{References}

[1] Shalwan A, Yousif BF. In State of Art: mechanical and tribological behaviour of polymeric composites based on natural fibres. Mater Des 2013;48:14-24. https:// doi.org/10.1016/j.matdes.2012.07.014.

[2] Shah DU. Developing plant fibre composites for structural applications by optimising composite parameters: a critical review. J Mater Sci 2013;48:6083-107. https://doi.org/10.1007/s10853-013-7458-7.

[3] Ramesh M, Palanikumar K, Hemachandra Reddy K. Plant fibre based biocomposites: sustainable and renewable green materials. Renew Sustain Energy Rev 2017;79:558-84. https://doi.org/10.1016/J.RSER.2017.05.094.

[4] Yan L, Chouw N, Jayaraman K. Flax fibre and its composites - a review. Compos B Eng 2014;56:296-317. https://doi.org/10.1016/J.COMPOSITESB.2013.08.014.

[5] Mastura MT, Sapuan SM, Mansor MR, Nuraini AA. Materials selection of thermoplastic matrices for 'green'" natural fibre composites for automotive antiroll bar with particular emphasis on the environment. Int J Precis Eng Manuf Green Technol 2018;5:111-9. https://doi.org/10.1007/s40684-018-0012-y.

[6] Rajmohan T, Vinayagamoorthy R, Mohan K. Review on effect machining parameters on performance of natural fibre-reinforced composites (NFRCs). J Thermoplast Compos Mater 2019;32:1282-302. https://doi.org/10.1177/ 0892705718796541.

[7] Vinayagamoorthy R, Rajmohan T. Machining and its challenges on bio-fibre reinforced plastics: a critical review. J Reinforc Plast Compos 2018;37:1037-50. https://doi.org/10.1177/0731684418778356.

[8] Lotfi A, Li H, Dao DV, Prusty G. Natural fiber-reinforced composites: a review on material, manufacturing, and machinability. J Thermoplast Compos Mater 2019. https://doi.org/10.1177/0892705719844546. 089270571984454.

[9] Wang D, Onawumi PY, Ismail SO, Dhakal HN, Popov I, Silberschmidt VV, et al. Machinability of natural-fibre-reinforced polymer composites: conventional vs ultrasonically-assisted machining. Compos Appl Sci Manuf 2019;119:188-95. https://doi.org/10.1016/J.COMPOSITESA.2019.01.028.

[10] Chegdani F, Mansori M El. Mechanics of material removal when cutting natural fiber reinforced thermoplastic composites. Polym Test 2018;67:275-83. https:// doi.org/10.1016/j.polymertesting.2018.03.016.

[11] Chegdani F, El Mansori M. New multiscale Approach for machining analysis of natural fiber reinforced bio-composites. J Manuf Sci Eng Trans ASME 2019;141: 11004. https://doi.org/10.1115/1.4041326.

[12] Hossain R, Islam A, Vuure A Van, Verpoest I. Processing dependent flexural strength variation of jute fiber reinforced epoxy composites. J Eng Appl Sci 2013;8: 513-8.

[13] Chegdani F, El Mansori M, Bukkapatnam S TS, Reddy JN. Micromechanical modeling of the machining behavior of natural fiber-reinforced polymer composites. Int J Adv Manuf Technol 2019;105:1549-61. https://doi.org/ 10.1007/s00170-019-04271-3.

[14] Arola D, Ramulu M. Orthogonal cutting of fiber-reinforced composites: a finite element analysis. Int J Mech Sci 1997;39:597-613. https://doi.org/10.1016/ S0020-7403(96)00061-6.

[15] Lasri L, Nouari M, El Mansori M. Modelling of chip separation in machining unidirectional FRP composites by stiffness degradation concept. Compos Sci Technol 2009;69:684-92. https://doi.org/10.1016/J. COMPSCITECH.2009.01.004.

[16] Chegdani F, Wang Z, El Mansori M, Bukkapatnam STS. Multiscale tribo-mechanical analysis of natural fiber composites for manufacturing applications. Tribol Int 2018;122:143-50. https://doi.org/10.1016/j.triboint.2018.02.030.

[17] Chegdani F, El Mansori M, Bukkapatnam STS, El Amri I. Thermal effect on the tribo-mechanical behavior of natural fiber composites at micro-scale. Tribol Int 2019. https://doi.org/10.1016/j.triboint.2019.06.024.

[18] Abaqus analysis user's manual. Abaqus 6.11 doc. Providence, RI, USA: Dassault Systèmes Simulia Corp.; 2011.

[19] Nayak D, Singh I, Bhatnagar N, Mahajan P. An analysis of machining induced damages in FRP composites - a micromechanics finite element approach. AIP Conf. Proc. 2004;712:327-31. https://doi.org/10.1063/1.1766545. AIP.

[20] Santiuste C, Soldani X, Miguélez MH. Machining FEM model of long fiber composites for aeronautical components. Compos Struct 2010;92:691-8. https:// doi.org/10.1016/J.COMPSTRUCT.2009.09.021.

[21] Ghidossi P, El Mansori M, Pierron F. Edge machining effects on the failure of polymer matrix composite coupons. Compos Appl Sci Manuf 2004;35:989-99. https://doi.org/10.1016/j.compositesa.2004.01.015.

[22] Baley C. Analysis of the flax fibres tensile behaviour and analysis of the tensile stiffness increase. Compos Appl Sci Manuf 2002;33:939-48. https://doi.org/ 10.1016/S1359-835X(02)00040-4.

[23] Charlet K, Baley C, Morvan C, Jernot JP, Gomina M, Bréard J. Characteristics of Hermès flax fibres as a function of their location in the stem and properties of the derived unidirectional composites. Compos Appl Sci Manuf 2007;38:1912-21. https://doi.org/10.1016/j.compositesa.2007.03.006.

[24] Hearle JWS. The fine structure of fibers and crystalline polymers. III. Interpretation of the mechanical properties of fibers. J Appl Polym Sci 1963;7:1207-23. https:// doi.org/10.1002/app.1963.070070403.

[25] Shah DU, Schubel PJ, Licence P, Clifford MJ. Determining the minimum, critical and maximum fibre content for twisted yarn reinforced plant fibre composites. Compos Sci Technol 2012;72. https://doi.org/10.1016/J. COMPSCITECH.2012.08.005. 1909-17.

[26] Yang J, Pan H, Li X, Sun S, Zhang H, Dong L. A study on the mechanical, thermal properties and crystallization behavior of poly(lactic acid)/thermoplastic poly (propylene carbonate) polyurethane blends. RSC Adv 2017;7:46183-94. https:// doi.org/10.1039/C7RA07424G. 
[27] Dittenber DB, GangaRao HVS. Critical review of recent publications on use of natural composites in infrastructure. Compos Appl Sci Manuf 2012;43:1419-29. https://doi.org/10.1016/j.compositesa.2011.11.019.

[28] Cardoso RPR, Adetoro OB. A generalisation of the Hill's quadratic yield function for planar plastic anisotropy to consider loading direction. Int J Mech Sci 2017; 128-129:253-68. https://doi.org/10.1016/j.ijmecsci.2017.04.024.

[29] Panamoottil SM, Das R, Jayaraman K. Towards a multiscale model for flax composites from behaviour of fibre and fibre/polymer interface. J Compos Mater 2017;51:859-73. https://doi.org/10.1177/0021998316654303.

[30] Hooputra H, Gese H, Dell H, Werner H. A comprehensive failure model for crashworthiness simulation of aluminium extrusions. Int J Crashworthiness 2004; 9:449-64. https://doi.org/10.1533/ijcr.2004.0289.

[31] Danas K, Ponte Castañeda P. Influence of the Lode parameter and the stress triaxiality on the failure of elasto-plastic porous materials. Int J Solid Struct 2012; 49:1325-42. https://doi.org/10.1016/J.IJSOLSTR.2012.02.006.

[32] Venu Gopala Rao G, Mahajan P, Bhatnagar N. Machining of UD-GFRP composites chip formation mechanism. Compos Sci Technol 2007;67:2271-81. https://doi. org/10.1016/J.COMPSCITECH.2007.01.025.

[33] Lee J-S, Jang J, Lee B-W, Choi Y, Lee SG, Kwon D. An instrumented indentation technique for estimating fracture toughness of ductile materials: a critical indentation energy model based on continuum damage mechanics. Acta Mater 2006;54:1101-9. https://doi.org/10.1016/J.ACTAMAT.2005.10.033.

[34] Park K, Choi H, Paulino GH. Assessment of cohesive traction-separation relationships in ABAQUS: a comparative study. Mech Res Commun 2016;78:71-8. https://doi.org/10.1016/J.MECHRESCOM.2016.09.004.

[35] Camanho PP, Davila CG, de Moura MF. Numerical simulation of mixed-mode progressive delamination in composite materials. J Compos Mater 2003;37: 1415-38. https://doi.org/10.1177/0021998303034505.
[36] Le Duigou A, Baley C, Grohens Y, Davies P, Cognard J-Y, Créach'cadec R, et al. A multi-scale study of the interface between natural fibres and a biopolymer. Compos Appl Sci Manuf 2014;65:161-8. https://doi.org/10.1016/J. COMPOSITESA.2014.06.010.

[37] Le Duigou A, Davies P, Baley C. Interfacial bonding of Flax fibre/Poly(l-lactide) bio-composites. Compos Sci Technol 2010;70:231-9. https://doi.org/10.1016/J. COMPSCITECH.2009.10.009.

[38] Merchant ME. Mechanics of the metal cutting process. I. Orthogonal cutting and a type 2 chip. J Appl Phys 1945;16:267. https://doi.org/10.1063/1.1707586.

[39] Wang F, Yin J, Ma J, Jia Z, Yang F, Niu B. Effects of cutting edge radius and fiber cutting angle on the cutting-induced surface damage in machining of unidirectional CFRP composite laminates. Int J Adv Manuf Technol 2017;91: 3107-20. https://doi.org/10.1007/s00170-017-0023-9.

[40] Sauer K, Witt M, Putz M. Influence of cutting edge radius on process forces in orthogonal machining of carbon fibre reinforced plastics (CFRP). Procedia CIRP 2019;85:218-23. https://doi.org/10.1016/J.PROCIR.2019.09.042.

[41] Ulutan D, Özel T. Methodology to determine friction in orthogonal cutting with application to machining titanium and nickel based alloys. In: ASME 2012 Int. Manuf. Sci. Eng. Conf., American Society of Mechanical Engineers; 2012. p. 327-34. https://doi.org/10.1115/MSEC2012-7275.

[42] Albrecht P. New developments in the theory of the metal-cutting process: Part I. The ploughing process in metal cutting. J Eng Ind 1960;82:348. https://doi.org/ 10.1115/1.3664242.

[43] Rao GVG, Mahajan P, Bhatnagar N. Micro-mechanical modeling of machining of FRP composites - cutting force analysis. Compos Sci Technol 2007;67:579-93. https://doi.org/10.1016/j.compscitech.2006.08.010. 